\title{
Effects of hypoxic training on physiological exercise intensity and recognition of exercise intensity in young men
}

\author{
Sohee Shin ${ }^{1}$, Shinichi Demura ${ }^{2}$, Bateer Shi ${ }^{1}$, Tsuneo Watanabe ${ }^{1}$, Tamotsu Yabumoto ${ }^{1}$, \\ Toshio Matsuoka ${ }^{1}$ \\ ${ }^{1}$ Department of Sports Medicine and Sports Science, Gifu University Graduate School of Medicine, Gifu, Japan \\ ${ }^{2}$ Kanazawa University Graduate School of Natural Science \& Technology, Kanazawa, Japan \\ Email: sohee@gifu-u.ac.jp
}

Received 10 January 2013; revised 13 February 2013; accepted 28 February 2013

\begin{abstract}
This study aimed to examine the effects of hypoxic training on physiological exercise intensity and recognition of exercise intensity in young men. The participants included 9 healthy young males $(23.2 \pm 6.5$ years old, $176.2 \pm 6.7 \mathrm{~cm}, 74.3 \pm 16.4 \mathrm{~kg}$ ). $\mathrm{VO}_{2}$ was measured during running with subjective exercise intensities of "somewhat hard" for $\mathbf{3}$ min and "fairly light" for $3 \mathrm{~min}$. After the measurements, the participants answered the question "what percentage of your maximal effort was performed during both running exercises." The exercise intensity recognition for the "fairly light" and "somewhat hard" intensities and the physiological exercise intensity measured by relative $\mathrm{VO}_{2}(\%)$ and relative heart rate (HR, \%) were then evaluated. The hypoxic training was performed 3 times a week for 4 weeks in a normobaric hypoxic chamber (oxygen concentration, $15.4 \%$ and altitude, $2500 \mathrm{~m}$ ). The participants ran at an exercise intensity of $60 \% \mathrm{VO}_{2 \max }$ for $40 \mathrm{~min}$ after a $5 \mathrm{~min}$ warm-up and then performed a 5 min cool-down. After training, they sat on a chair in the same room for $30 \mathrm{~min} . \mathrm{VO}_{2 \max }$ and $\mathrm{HR}_{\max }$ changed significantly after the training. At "fairly light" intensity, the physiological measures were significantly higher than recognition of exercise intensity, with relative $\mathrm{VO}_{2}(\%)$ increasing after training. In conclusion, hypoxia training causes an increase in $\mathrm{VO}_{2 \max }$ and physiological exercise intensity during running at a "fairly light” intensity.
\end{abstract}

Keywords: Hypoxic Training; Relative $\mathrm{O}_{2}$; Relative HR; Recognition of Exercise Intensity

\section{INTRODUCTION}

Habitually performing aerobic exercises aimed at improving cardiovascular fitness is widely recommended
[1]. It is desirable to use an index based on physiological parameters for determining aerobic exercise load [1]. However, more cases can help to determine exercise intensity using subjective measures (i.e., self-selected intensity) rather than physiological indices. However, factors such as physique, exercise ability, exercise experience, and the environment may affect self-selected intensity. In short, even if each person was instructed to run with the same exercise intensity, the intensity selected may differ because of the above factors.

Okura et al. [2] reported that people who did not exercise chose significantly higher relative exercise intensity as their favorite intensity than those who did exercise, with their feeling of comfort after exercise being significantly lower. Hayashi et al. [1] also reported that exercise characteristics which participants had experienced in the past caused differences in cognition ability to determine the intensity imposed on their body during exercise. As a consequence this affected self-selected intensity. As stated above, although the effects of exercise habit and experience on cognition of exercise intensity have been examined, there is limited information on the effects of environmental factors. Participants may recognize higher exercise intensity by hypoxia even if the intensity is lower than with normoxia because hypoxia itself affects the body in a manner similar to a large load in low oxygen environment.

Hypoxia has been used as a method in altitude training for competitive sports $[3,4]$. The partial pressure of oxygen in the atmosphere is decreased at high attitudes or in a low-pressure chamber. Consequently, the decline in $\mathrm{SpO}_{2}$ in human blood causes a lack of oxygen supply to body tissues. Hypoxia training is a method that aims to improve $\mathrm{O}_{2}$ transport ability, cardiovascular fitness, and competitive performances by using anoxia to stimulate the body (i.e., environmental stimulation) [5]. HR and $\mathrm{VO}_{2}$ levels in hypoxic training are greater than or equal to those during training in a normoxic environment, even at low exercise intensity. 
Numerous studies have been performed on the relationships between hypoxia training and aerobic exercise ability or competitive performances [6-8]. However, the effects of hypoxia training on recognition of exercise intensity and physiological exercise intensity during submaximal exercise have not been investigated extensively.

Therefore, the purpose of this study was to examine the effects of hypoxic training on physiological exercise intensity and recognition of exercise intensity in young men.

\section{METHODS}

\subsection{Participants}

The participants included 9 healthy young males (age, $23.2 \pm 6.5$ years old; height, $176.2 \pm 6.7 \mathrm{~cm}$; weight, 74.3 $\pm 16.4 \mathrm{~kg}$ ). As a result of a hearing survey, 3 of the 9 subjects carried out club activities regularly, but did not have the habit of jogging. The purpose and procedure of the study were explained in detail and informed consent was obtained from all the participants. The study was approved by the Ethics Committee on Human Experimentation of Faculty of Education, Kanazawa University (No. 19-19).

\subsection{Running at Each Rate of Perceived Exertion (RPE) and Measurement of $\mathrm{VO}_{2}$ and $\mathrm{VO}_{2 \text { max }}$}

The above measurements were conducted before and after training in a normoxia laboratory at Gifu University Sports Medicine and Sports Science. $\mathrm{VO}_{2}$ and $\mathrm{VO}_{2 \max }$ were measured by a pulmonary exercise test monitoring system ( $\mathrm{V}_{\max }$, Nihon Cohden, Tokyo, Japan) using the following steps.

Procedure of $\mathrm{VO}_{2}$ and $\mathrm{VO}_{2 \max }$ measurements before and after training:

STEP 1: Measurement of heart rate and blood pressure at rest.

STEP 2: Warm-up (stretch and walk on the treadmill for $5 \mathrm{~min}$ each) (please see Section 2.2.1);

STEP 3: Run on the treadmill at "fairly light" intensity for 3 min with measurement of $\mathrm{HR}$ and $\mathrm{VO}_{2}$ (please see Section 2.2.2);

STEP 4: Run on the treadmill at "somewhat hard" intensity for $3 \mathrm{~min}$ with measurement of $\mathrm{HR}$ and $\mathrm{VO}_{2}$ (please see Section 2.2.2);

STEP 5: Run on the treadmill until exhausted with measurement of $\mathrm{HR}_{\max }$ and $\mathrm{VO}_{2 \max }$ (please see Section 2.2.4);

STEP 6: Survey on recognition of exercise intensity (please see Section 2.2.3);

\subsubsection{Preparation for Measurement}

Resting HR and blood pressure of the participants were measured before the warm-up. For the warm-up, the participants stretched for $5 \mathrm{~min}$ and then walked at $4 \mathrm{~km} / \mathrm{h}$ on the treadmill for $5 \mathrm{~min}$. During this time, a mask that fitted the face was regulated and checked to ensure that air was not leaking from it during walking.

\subsubsection{Run on the Treadmill at Subjective Exercise Intensity with Measurements of $\mathrm{HR}$ and $\mathrm{VO}_{2}$}

Hayashi et al. (2003) reported that participants could recognize intensity more accurately during exercise at moderate or high intensities than at low intensity. In this regard, the running exercise was performed in the order of low intensity (fairly light) and moderate (somewhat hard) in this study. Participants ran on the treadmill at a subjective "fairly light" intensity for $3 \mathrm{~min}$ and after a 5 min walk at a subjective "somewhat hard" intensity for 3 min. They voluntarily adjusted their speed using the speed adjustment button. The speed was not displayed during running. Speed was adjusted for the first minute of each exercise intensity.

\subsubsection{Recognition of Exercise Intensity}

After the measurements the participants answered the question "what percentage of maximal effort was the exercise (running) performed during 'fairly light' and 'somewhat hard' exercise intensities".

Questions on exercise intensity recognition:

1) What percentage of maximal intensity was used to perform "somewhat hard" exercise?

2) What percentage of maximal intensity was used to perform "fairly light" exercise?

\subsubsection{Measurement of $\mathrm{VO}_{2 \max }$}

$\mathrm{VO}_{2 \max }$ was measured using the modified Astrand protocol [9]. Participants ran at $70 \% \mathrm{HR}$ for $3 \mathrm{~min}$. The angle of the gradient was then increased by $2 \%$ every 2 min until exhaustion. Using this protocol and a constant speed carries a slight risk of falling while running, but $\mathrm{VO}_{2 \max }$ can be measured accurately within a short time. $\mathrm{VO}_{2}$ was recorded continuously using a "breath-bybreath" method, simultaneously with measurement of HR. In addition, RPE (ratings of perceived exertion) during $\mathrm{VO}_{2 \max }$ measurement was recorded every 2 min by a research investigator.

\subsubsection{Parameters}

The following parameters were used to examine differences between physiological exercise intensity (\%) and recognition of exercise intensity during runs at "fairly light" and "somewhat hard" intensity.

1) Physiological parameters

a) $\mathrm{VO}_{2 \max }(\mathrm{ml} / \mathrm{kg} / \mathrm{min})$.

b) HR (BPM; beats per minute).

c) $\mathrm{VO}_{2}$ when running at "fairly light" and "somewhat 
hard" exercise intensity.

d) HR when running at "fairly light" and "somewhat hard" exercise intensity.

The means of $\mathrm{VO}_{2}$ and HR in the final min of the three min run were used in the analyses.

2) Physiological exercise intensity

Physiological exercise intensities were calculated using the following equations:

a) Relative $\mathrm{VO}_{2}(\%)=\left\{\mathrm{VO}_{2} / \mathrm{VO}_{2 \max }\right\} \times 100$.

b) Relative

$$
\begin{aligned}
& \mathrm{HR}(\%) \\
= & \left\{\left(\mathrm{HR}-\mathrm{HR}_{\text {rest }}\right) /\left(\mathrm{HR}_{\text {max }}-\mathrm{HR}_{\text {at rest }}\right)\right\} \times 100 .
\end{aligned}
$$

3) Recognition of exercise intensity.

Parameters on recognition of exercise intensity included subjective recognition of "fairly light" and "somewhat hard" intensities (Note: see Section 2.3. Exercise intensity recognition).

\subsection{Hypoxic Training (Figure 1)}

Participants performed hypoxic training in a normobaric hypoxic chamber set at an altitude of 2500 meters (oxygen level $15.4 \%$ ). The participants ran at an exercise intensity of $60 \% \mathrm{VO}_{2}$ for $40 \mathrm{~min}$ after a 5 min warm-up and then performed a 5 min cool-down. After training, they sat on a chair and rested in the same room for 30 min. The hypoxic training was performed 3 times a week for 4 weeks. Training in this study used the same treadmill run for measuring changes in $\mathrm{VO}_{2 \max }$.

\subsection{Statistical Analyses}

Paired t-tests were used to assess the mean differences between before- and after-training values for $\mathrm{VO}_{2 \max }$, $\mathrm{HR}_{\text {max }}$, and $\mathrm{VO}_{2}$ and $\mathrm{HR}$ during the subjective intensity runs ("fairly light" and "somewhat hard"). A repeatedmeasures two-way ANOVA was used to assess mean differences between recognition of exercise intensity and physiological exercise intensities (relative HR, relative $\mathrm{VO}_{2}$ ) ANOVA included before and after training as Factor 1 and exercise intensity recognition and physiological exercise intensity as Factor 2. Tukey's HSD method was used for multiple comparison of significant variables. A probability level of $p<0.05$ was considered statistically significant. The effect of size was calculated to assess the size of the mean differences.

\section{RESULTS}

Table 1 shows the mean differences in $\mathrm{VO}_{2 \max }$ and $\mathrm{HR}_{\max }$ before and after training. Significant differences were found for both parameters, with $\mathrm{VO}_{2 \max }$ being greater after training and $\mathrm{HR}_{\max }$ being higher before training ( $\mathrm{ES}=1.26$ and 0.39 , respectively).

Table 2 shows the mean differences in $\mathrm{VO}_{2}$ and $\mathrm{HR}$ before and after training during the subjective intensity runs ("fairly light" and "somewhat hard"). $\mathrm{VO}_{2}$ was greater after training than before training at both exercise intensities.

Table 3 shows the mean differences between recognition of exercise intensity and relative $\mathrm{VO}_{2}$. Significant main effects [exercise intensity recognition and relative $\mathrm{VO}_{2}$ (F1) and before and after training (F2)] were only found during fairly light intensity exercise. Multiple comparison showed that the difference between recognition of exercise intensity (\%) and relative $\mathrm{VO}_{2}$ was larger after training and that relative $\mathrm{VO}_{2}$ was larger than recognition of exercise intensity.

Table 4 shows the mean differences between recognition of exercise intensity and relative HR. A significant difference was found between the main effect of exercise intensity recognition and relative HR (F1) only during "fairly light" intensity exercise. Multiple comparison showed that relative HR was larger than recognition of exercise intensity.

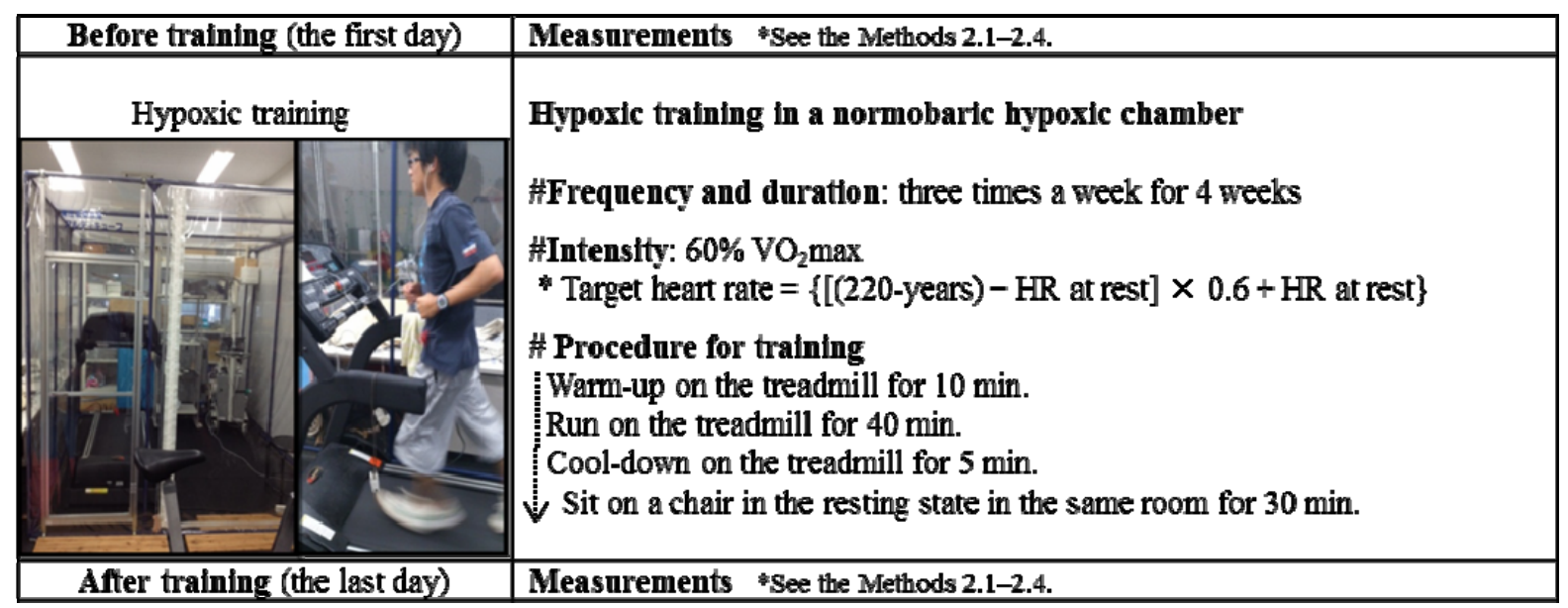

Figure 1. The procedure for hypoxic training. 
Table 1. Mean differences in $\mathrm{VO}_{2 \max }$ and $\mathrm{HR}_{\max }$ before and after training $(\mathrm{n}=9)$.

\begin{tabular}{cccccccc}
\hline & \multicolumn{2}{c}{ Before training } & \multicolumn{2}{c}{ After training } & \multicolumn{2}{c}{ Paired t-test } \\
\hline Parameters & Mean & SD & Mean & SD & t-value & p-value & ES \\
\hline $\begin{array}{c}\mathrm{VO}_{2 \max } \\
(\mathrm{ml} / \mathrm{kg} / \mathrm{min})\end{array}$ & 51.2 & 9.2 & 62.6 & 8.8 & 4.3 & $0.00^{*}$ & 1.26 \\
$\mathrm{HR}(\mathrm{BPM})$ & 193.6 & 13.5 & 188.9 & 10.6 & 2.0 & 0.04 & 0.39 \\
\hline
\end{tabular}

${ }^{*} \mathrm{p}<0.05 / 2$; ES: effect size.

Table 2. Mean differences in $\mathrm{VO}_{2}$ and $\mathrm{HR}$ during subjective intensity runs before and after training $(\mathrm{n}=9)$.

\begin{tabular}{cccccccccc}
\hline & \multirow{2}{*}{ Parameters } & \multirow{2}{*}{ Subjective exercise intensity } & \multicolumn{2}{c}{ Before training } & \multicolumn{2}{c}{ After training } & \multicolumn{3}{c}{ Paired t-test } \\
\cline { 3 - 8 } & & Mean & SD & Mean & SD & t-value & p-value & ES \\
\hline \multirow{2}{*}{$\mathrm{VO}_{2}(\mathrm{ml} / \mathrm{kg} / \mathrm{min})$} & Fairly light & 25.6 & 5.4 & 33.6 & 4.3 & 3.4 & $0.01^{*}$ & 1.64 \\
& Somewhat hard & 33.4 & 6.8 & 40.0 & 5.1 & 2.4 & $0.02^{*}$ & 1.09 \\
$\mathrm{HR}(\mathrm{BPM})$ & Fairly light & 132.3 & 16.4 & 133.9 & 18.7 & 0.6 & 0.28 & 0.09 \\
& Somewhat hard & 156.3 & 17.0 & 152.4 & 17.8 & 1.2 & 0.13 & 0.22 \\
\hline
\end{tabular}

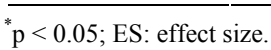

Table 3. Mean differences between recognition of exercise intensity and relative $\operatorname{VO}_{2}(n=9)$.

\begin{tabular}{|c|c|c|c|c|c|c|c|c|c|}
\hline \multirow{2}{*}{$\begin{array}{l}\text { Subjective exercise } \\
\text { intensity }\end{array}$} & \multirow{2}{*}{ Training } & \multicolumn{2}{|c|}{ REI (\%) } & \multicolumn{2}{|c|}{ Relative $\mathrm{VO}_{2}(\%)$} & \multicolumn{3}{|c|}{ Two-way ANOVA } & \multirow[b]{2}{*}{ Tukey's HSD } \\
\hline & & Mean & SD & Mean & SD & & value & p-value & \\
\hline \multirow{3}{*}{ Fairly light } & Before training & 28.9 & 6.0 & 49.9 & 3.3 & F1 & 174.53 & $0.00^{*}$ & Before and after training: $\mathrm{REI}<$ Relative $\mathrm{VO}_{2}$ \\
\hline & After training & 36.7 & 7.1 & 54.2 & 5.7 & F2 & 6.33 & $0.03^{*}$ & REI, Relative $\mathrm{VO}_{2}$ : before $<$ after training \\
\hline & & & & & & F3 & 1.37 & 0.27 & \\
\hline \multirow{3}{*}{ Somewhat hard } & Before training & 63.3 & 7.1 & 65.0 & 3.6 & $\mathrm{~F} 1$ & 1.49 & 0.26 & $\mathrm{n} . \mathrm{s}$ \\
\hline & After training & 61.1 & 3.3 & 64.4 & 7.4 & $\mathrm{~F} 2$ & 0.42 & 0.53 & \\
\hline & & & & & & F3 & 0.49 & 0.50 & \\
\hline
\end{tabular}

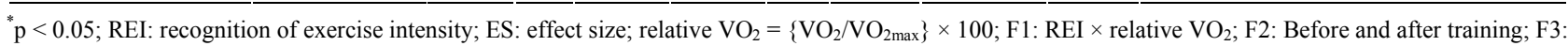
interaction.

Table 4. Mean differences between recognition of exercise intensity and relative HR $(n=9)$.

\begin{tabular}{|c|c|c|c|c|c|c|c|c|c|}
\hline \multirow{2}{*}{$\begin{array}{l}\text { Subjective exercise } \\
\text { intensity }\end{array}$} & \multirow{2}{*}{ Training } & \multicolumn{2}{|c|}{ REI (\%) } & \multicolumn{2}{|c|}{ Relative HR (\%) } & \multicolumn{3}{|c|}{ Two-way ANOVA } & \multirow[b]{2}{*}{ Tukey's HSD } \\
\hline & & Mean & SD & Mean & $\mathrm{SD}$ & & alue & p-value & \\
\hline \multirow{3}{*}{ Fairly light } & Before training & 28.9 & 6.0 & 46.1 & 8.6 & $\mathrm{~F} 1$ & 13.50 & $0.01 *$ & Before and after training: $\mathrm{REI}<$ Relative $\mathrm{HR}$ \\
\hline & After training & 36.7 & 7.1 & 49.4 & 14.0 & $\mathrm{~F} 2$ & 4.00 & 0.08 & REI: before $<$ after training \\
\hline & & & & & & $\mathrm{F} 3$ & 1.50 & 0.26 & \\
\hline \multirow{3}{*}{ Somewhat hard } & Before training & 63.3 & 7.1 & 67.1 & 7.0 & $\mathrm{~F} 1$ & 4.00 & 0.08 & n.s \\
\hline & After training & 61.1 & 3.3 & 66.9 & 9.3 & $\mathrm{~F} 2$ & 0.60 & 0.44 & \\
\hline & & & & & & F3 & 0.30 & 0.58 & \\
\hline
\end{tabular}

${ }_{\mathrm{p}}^{*}<0.05$; REI: recognition of exercise intensity; ES: effect size; relative HR: $\left\{\left(\mathrm{HR}-\overline{\left.\left.\mathrm{HR}_{\text {at rest }}\right) /\left(\mathrm{HR}_{\max }-\mathrm{HR}_{\text {at rest }}\right)\right\} \times 100 ; \mathrm{F} 1: \mathrm{REI} \times \text { relative HR; F2: Before }}\right.\right.$ and after training; F3: interaction. 


\section{DISCUSSION}

This study examined the effects of hypoxic training on physiological exercise intensity and recognition of exercise intensity in young men.

$\mathrm{VO}_{2 \max }$ increased after hypoxic training for 4 weeks. Haga and Ohno [10] classified endurance capacity into maximal ability such as $\mathrm{VO}_{2 \max }$ and submaximal ability as LT and emphasized that it is necessary to perform training to enhance both $\mathrm{VO}_{2 \max }$ and LT level to improve whole cardiovascular fitness. They also reported that high exercise intensity is important for improving $\mathrm{VO}_{2 \max }$ [10]. The current study used $60 \% \mathrm{VO}_{2 \max }$ as the exercise intensity for hypoxic training. $\mathrm{VO}_{2 \max }$ increased markedly after training ( $\mathrm{ES}=1.0)$ despite this being performed at moderate intensity. $\mathrm{VO}_{2}$ during subjective exercise intensity also increased after training.

$\mathrm{VO}_{2 \max }$ at high altitude decreases exponentially by approximately $10 \%$ with every rise of $1000 \mathrm{~m}$ [11]. This decrease is attributed to decreased oxygen supply to tissues that involves a decrease in $\mathrm{CaO}_{2}$ and $\mathrm{SpO}_{2}$ [12]. Hypoxic training by maintaining hypoxia for a given period of time is therefore expected to result in a stimulatory effect in addition to improving the cardiorespiratory response at rest [13]. The ability to transport oxygen to tissues shifts from an acute adaptation to a chronic adaptation when during hypoxic training continually for a certain period [14]. This represents altitude acclimation [14], which may contribute to an increase in $\mathrm{VO}_{2 \max }$ and a decrease in HR with increased cardiac output (i.e., an increase in cardiovascular fitness).

On the other hand, recognition of exercise intensity was lower for "fairly light" intensity exercise than for physiological exercise intensity (relative HR, relative $\mathrm{VO}_{2}$ ) both before and after training. In short, this infers that participants ran with higher intensity than during subjective exercise intensity. In addition, relative $\mathrm{VO}_{2}$ was also higher after training than before training. As the increase in $\mathrm{VO}_{2}$ relative to increased $\mathrm{VO}_{2 \max }$ was high ("fairly light" intensity $\mathrm{VO}_{2}$ before-training of $49.9 \%$ for $\mathrm{VO}_{2 \max } 51.2 \mathrm{ml} / \mathrm{kg} / \mathrm{min}$ vs after-training of $54.2 \%$ for $\mathrm{VO}_{2 \max } 62.6 \mathrm{ml} / \mathrm{kg} / \mathrm{min}$ indicates that the participants considered physiological exercise intensity was "fairly light" after training compared with before training even if they exercised at high intensity.

Imakawa [14] and Kacin et al., [15] reported that if people performed endurance training at high attitude with the same intensity as that at sea level, the hypoxic stimulation to tissues at high altitude may be increased because of the relative exercise intensity being increased compared with that at sea level. In our study, the participants felt comfortable running at pace in normoxic conditions because of the effect of hypoxic training, which may have influenced the physiological exercise intensity of "fairly light" intensity. Asano and Kobayashi [16] also reported that RPE in a 3 min run test conducted before and after a short period of hypoxic training (altitude: $2400 \mathrm{~m}$ ) tended to decrease after training even during a run at the same speed under normoxic conditions.

Training in this study was performed in a normobaric hypoxic chamber instead of at high attitude, although it is inferred that the participants ran comfortably even if the exercise intensity was higher after training than before training.

However, there was no difference between recognition of exercise intensity and physiological exercise intensity. In short, "somewhat hard" intensity was approximately $65 \%(61.1 \%-67.1 \%)$ of $\mathrm{HR}$ and $\mathrm{VO}_{2 \max }$ and was similar to physiological exercise intensity and recognition of exercise intensity. Robertson et al. [17] and Hayashi et al. [18] reported that people recognized fatigue in breathing and metabolism with emphasis on physical fatigue awareness at $70 \% \mathrm{VO}_{2 \max }$. This was similar to the "somewhat hard" exercise intensity used in this study (approximately $65 \%$ ). When subjective exercise intensity is greater than moderate intensity, recognition of exercise intensity which people perceive subjectively agrees roughly with the intensity of physiological exercise. However, it is inferred that if it is low, the difference between both sides becomes larger and physiological exercise intensity is higher than recognition of exercise intensity. This study had not control group, and the sample size were small. Hence, further study is needed to examine the effects of hypoxic training on physiological exercise intensity and recognition of exercise intensity from comparisons with normoxic group.

\section{CONCLUSION}

After hypoxic training, both $\mathrm{VO}_{2 \max }$ and $\mathrm{VO}_{2}$ increased during runs at "fairly light" and "somewhat hard" intensities. Physiological exercise intensity during running at "fairly light" intensity was higher than subjective recognition of exercise intensity. At "fairly light" intensity, physiological exercise intensity was increased after hypoxic training. Physiological exercise intensity and recognition of exercise intensity during a run at "somewhat hard" intensity are similar. In conclusion, hypoxia training causes an increase in $\mathrm{VO}_{2 \max }$ and physiological exercise intensity during a run at "fairly light" intensity.

\section{REFERENCES}

[1] Hayashi, Y., Okura, T., Nakagaichi, M. and Tanaka, K. (2003) The influence of moderate- and high-intensity exercise on perception of exercise intensity and physiological variables during self-selected aerobic exercise. Japanese Society of Physical Education, 48, 299-312.

[2] Okura, T., Hayashi, Y., Wada, M. and Tanaka, K. (2000) 
Effect of exercise habit on the cardiorespiratory and psychological responses to self-prescribed intensities. Japanese Society of Physical Education, 45, 201-212.

[3] Bailey, D.M. and Davies, B. (1997) Physiological implications of altitude training for endurance performance at sea level: A review. British Journal of Sports Medicine, 31, 183-190. doi:10.1136/bjsm.31.3.183

[4] Roels, B., Bentley, D.J., Coste, O., Mercier, J. and Millet, G.P. (2007) Effects of intermittent hypoxic training on cycling performance in well-trained athletes. European Journal of Applied Physiology, 101, 359-368. doi:10.1007/s00421-007-0506-8

[5] Ookura, M., Yoshida, R., Yamamoto, I. and Fujiwara, T. (2006) Research on application of low oxygen environment to therapeutic exercise: Trials in normal air pressure and low oxygen room. The Journal of Japan Academy of Health Sciences, 8, 227-233.

[6] Millet, G.P., Roels, B., Schmitt, L., Woorons, X. and Richalet, J.P. (2010) Combining hypoxic methods for peak performance. Sports Medicine, 40, 1-25. doi:10.2165/11317920-000000000-00000

[7] Wilber, R.L, Stray-Gundersen, J. and Levine, B.D. (2007) Effect of hypoxic "dose" on physiological responses and sea-level performance. Medicine and Science in Sports and Exercise, 39, 1590-1599. doi:10.1249/mss.0b013e3180de49bd

[8] Saunders, P.U., Pyne, D.B. and Gore, C.J. (2009) Endurance training at altitude. High Altitude Medicine \& Biology, 10, 135-148. doi:10.1089/ham.2008.1092

[9] Pollock, M.L, Wilmore, J.H. and Fox, S.M. (1984) Exercise in health and disease: Evaluation and prescription for prevention and rehabilitation. W. B. Saunders, Co., Philadelphia.
[10] Haga, S. and Ohno, H. (2003) Training physiology. Kyorin, Tokyo.

[11] Asano, K. (1999) Trends and practice of high-altitude training. Physiological significance of high-altitude training and recent trends. The Journal of Clinical Sports Medicine, 16, 505-516.

[12] Bert, P. (1943) Barometric pressure: Researches in experimental physiology. College Book Co., Columbus. doi:10.5962/bhl.title.6434

[13] Bailey, D.M. and Davies, B. (1997) Physiological implications of altitude training for endurance performance at sea level: A review. British Journal of Sports Medicine, 31, 183-190. doi:10.1136/bjsm.31.3.183

[14] Imakawa, S. (2008) Molecular biology on high altitude hypoxic training. Igakuno Ayumi, 225, 1287-1292.

[15] Kacin, A., Golja, P. and Eiken, O., Tipton, M.J. and Mekjavic, I.B. (2007) The influence of acute and 23 days of intermittent hypoxic exposures on the exercise-induced forehead sweating response. European Journal of Applied Physiology, 99, 557-566. doi:10.1007/s00421-006-0364-9

[16] Asano, K. and Kobayashi, K. (2004) Science of altitude training. Kyorin, Tokyo.

[17] Robertson, R.J., Gillespie, R.L., McCarthy, J. and Rose, K.D. (1979) Differentiated perceptions of exertion: Part II. Relationship to local and central physiological responses. Perceptual \& Motor Skills, 49, 691-697. doi:10.2466/pms.1979.49.3.691

[18] Hayashi, Y., Suzuki, K., Numao, S. and Tanaka, K. (2007) Interrelation between serial changes in physiological factors and perceived exertion during self-selected aerobic exercise. Japanese Society of Physical Education, 52, 119-131. 